8. INSPIRE Network Service Architecture Version 3.0. INSPIRE NS DT, 2008.

9. OpenGIS ${ }^{\circledR}$ Web Processing Service. Version 1.1.0. OGC, 2007. http://www.opengeospatial.org/standards/wps

10. Software As A Service: Strategic Backgrounder. Software \& Information Industry Association, Washington, D.C., 28 February 2001.

МОДЕЛИРОВАНИЕ ГИДРОТЕХНИЧЕСКИХ ПРОЕКТОВ УЛУЧШЕНИЯ ГИДРОЛОГИЧЕСКОГО РЕЖИМА С ПРИМЕНЕНИЕМ ГИС-ТЕХНОЛОГИЙ НА ПРИМЕРЕ ВОЛГО-АХТУБИНСКОЙ ПОЙМЫ

\author{
Писарев А.В., Елисеева М.В., Храпов С.С., Хоперсков А.В., Воронин А.А. \\ Волгоградский государственный университет, infomod@volsu.ru
}

\title{
SIMULATION OF HYDRAULIC PROJECTS FOR IMPROVING HYDROLOGICAL MODE OF VOLGA-AKHTUBA FLOODPLAIN WITH GIS TECHNOLOGY USAGE
}

\author{
Pisarev A.V., Eliseeva M.V., Khrapov S.S., Khoperskov A.V., Voronin A.A. \\ Volgograd State University, infomod@volsu.ru
}

\begin{abstract}
The paper describes the mechanism of hydrological network behavior of northern part of the Volga-Akhtuba floodplain during the spring flood. The processes which changed the influence of regulated flow over the past few years were investigated. We examine project of geographic information system designed to improve the status of water bodies to a level ensuring the conservation of biodiversity, improving provision of the population and economy of water resources and increasing the level of protection of population and economy from the negative effects of water.
\end{abstract}

\section{АННОТАЦИЯ}

В работе описан механизм динамики гидрологической сети северной части ВолгоАхтубинской поймы во время весеннего половодья. Проведена характеристика изменений паводковых процессов за последние несколько лет под влиянием зарегулированного стока. Рассматривается проект геоинформационной системы, предназначенной для улучшения состояния водных объектов до уровня, обеспечивающего сохранение биоразнообразия, повышение уровня обеспеченности населения и объектов экономики водными ресурсами и повышение уровня защищенности населения и объектов экономики от негативного воздействия вод.

\section{1. ВВЕДЕНИЕ}

В XX веке естественный водный режим Волги изменился. С постройкой 11 гидроэлектростанций на реках Волга и Кама и образованием ряда водохранилищ сток стал зарегулированным. Если ранее под таянием снегов наблюдалось неконтролируемое весеннее 
половодье, обеспечивающее нормальное функционирование прилегающих территорий, то сейчас сток Волги представляет собой искусственный попуск, в формировании которого, в первую очередь, учитывается хозяйственная деятельность. Особо сильно такой режим сказывается на Нижней Волге - территории от Волжской ГЭС до Каспийского моря. Данная территория включает Волго-Ахтубинскую пойму (ВАП), дельту Волги и район Западных подстепенных ильменей [Горелиц, 2013]. Объем воды, поступающий в нижний бьеф Волжской ГЭС является важнейшим фактором, влияющим на условия существования уникальных экосистем региона.

Весеннее половодье на Нижней Волге сопровождается затоплением пойменных территорий. Это позволяет наполнять водой временные и постоянные водоемы и водотоки, решая задачи сельского хозяйства, водообеспечения хозяйственных объектов и населения. И, разумеется, обеспечивая возможность нереста рыбы.

В последние годы, помимо зарегулированного стока, сильно возросла антропогенная нагрузка на территорию Волго-Ахтубинской поймы. Активное осваивание территорий, в первую очередь для жилья, привело к изменению гидрологического режима. Строительство незаконных дамб, замусоривание водотоков, увеличенный водозабор и самостоятельное изменение русел ериков - все это привело к изменению механизма заливания пойменных территорий.

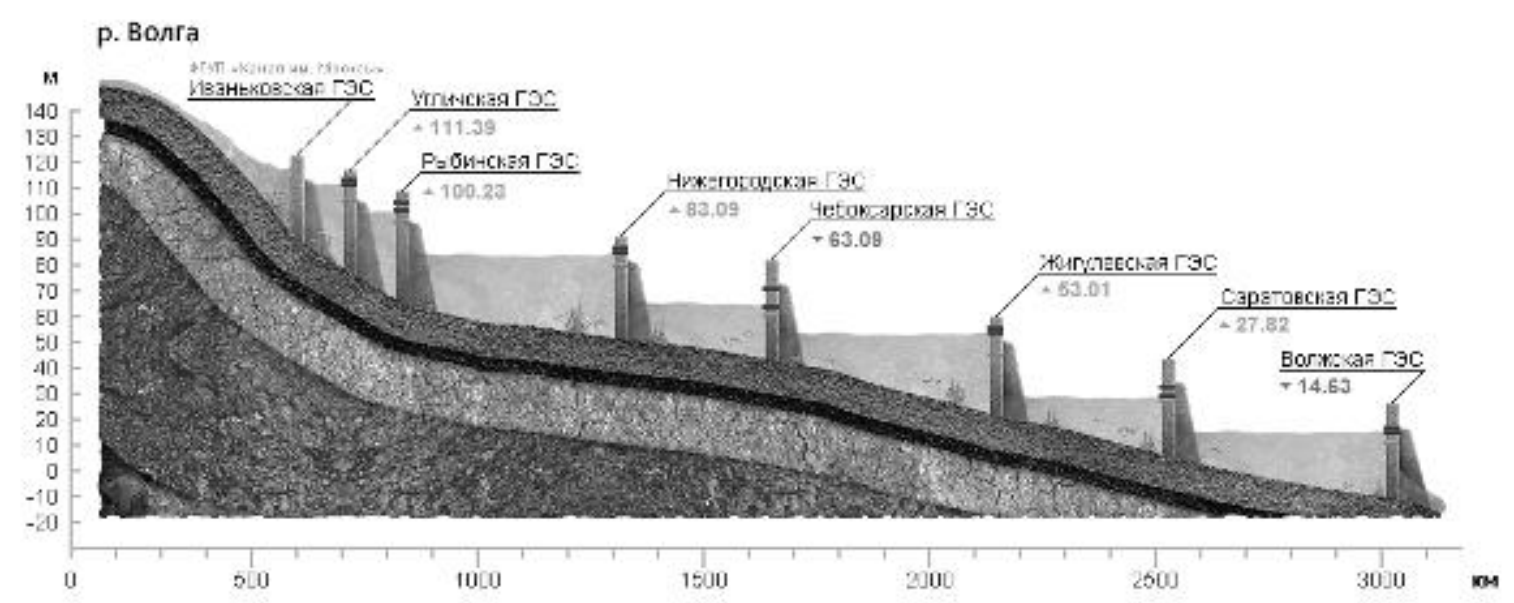

Рис. 1. Каскад ГЭС на р. Волга

\section{2. МЕХАНИЗМ ЗАТОПЛЕНИЯ ВОЛГО-АХТУБИНСКОЙ ПОЙМЫ ВО ВРЕМЯ} ПАВОДКОВ

Территория весеннего стока, характеризуемая наибольшими положительными уклонами поверхности и расходами воды выглядит следующим образом: от Волги отходит река Ахтуба, от которой, в свою очередь происходит сток в Волгу через разветвленную сеть водотоков ериков. На рис. показан Каширинский водохозяйственный тракт 


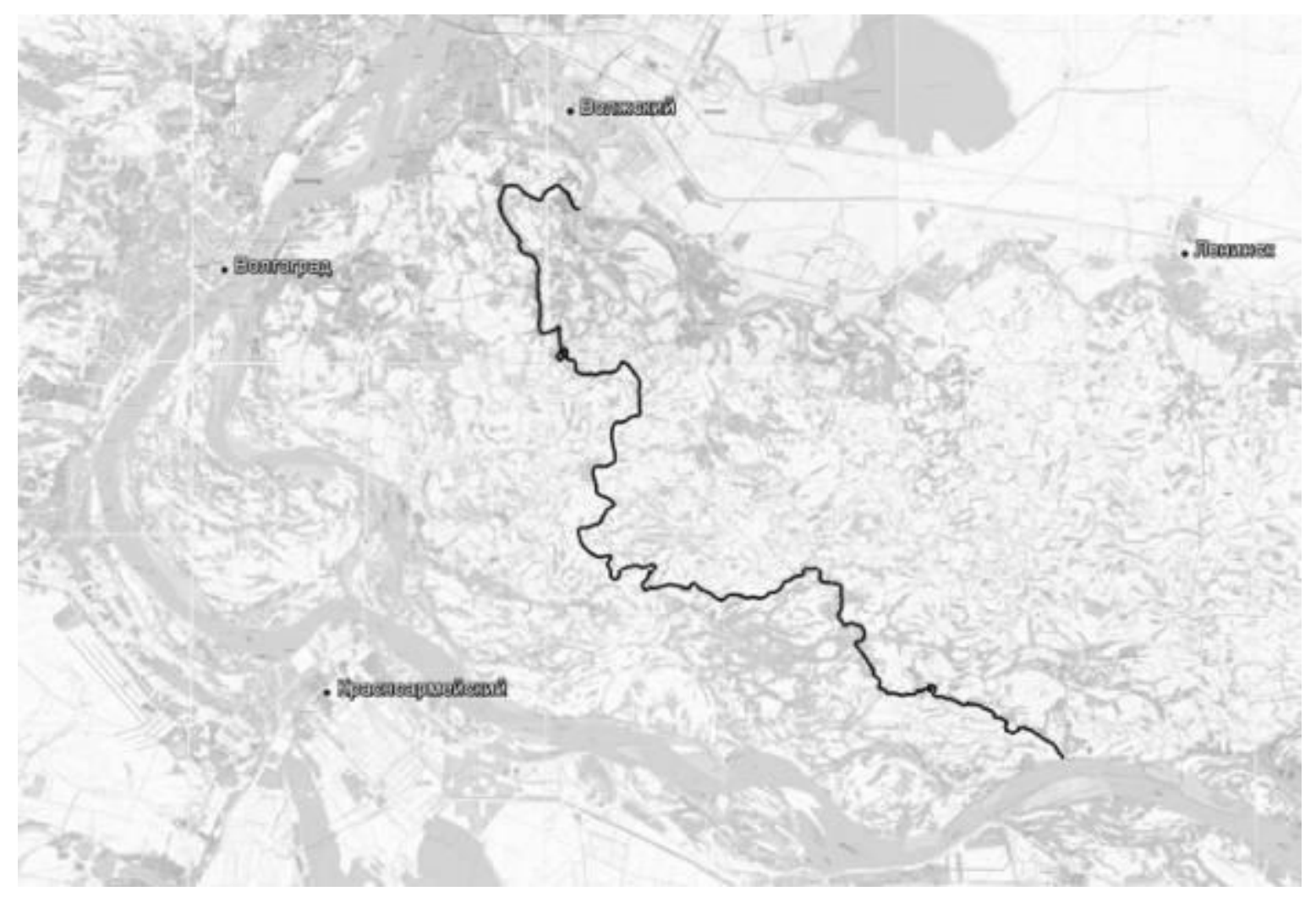

Рис 2. Каширинский тракт Волго-Ахтубинской поймы (исток - p. Ахтуба, устье - p. Волга)

На основе ряда исследований [Khrapov, 2013], были определены основные факторы, характеризующие затопление ВАП. Их можно разделить на три группы:

1. Динамика поверхностных вод во время весеннего паводка. Роль весеннего половодья выполняют сезонные попуски воды через створ плотины Волжской ГЭС в объеме $V \sim 20$ км$^{3}$. Интегральной величины $V$ недостаточно для характеристики эффективности сброса, под которым в первом приближении можно принять максимальное заполнение малых водоемов Волго-Ахтубинской поймы (озера, ерики, протоки). Наблюдения и результаты моделирования указывают на сильную зависимость последствий попуска воды от характера временной функции темпа сброса $Q(t)=d V / d t$, которая называется гидрографом [Хоперсков, 2011]. Из гидрографа возможно узнать параметры гидрологического режима такие как:

- продолжительность подъема и спада уровня воды,

- скорость подъема и спада уровня воды,

- продолжительность стояния максимальных уровней воды,

- попуск воды в разные дни. 


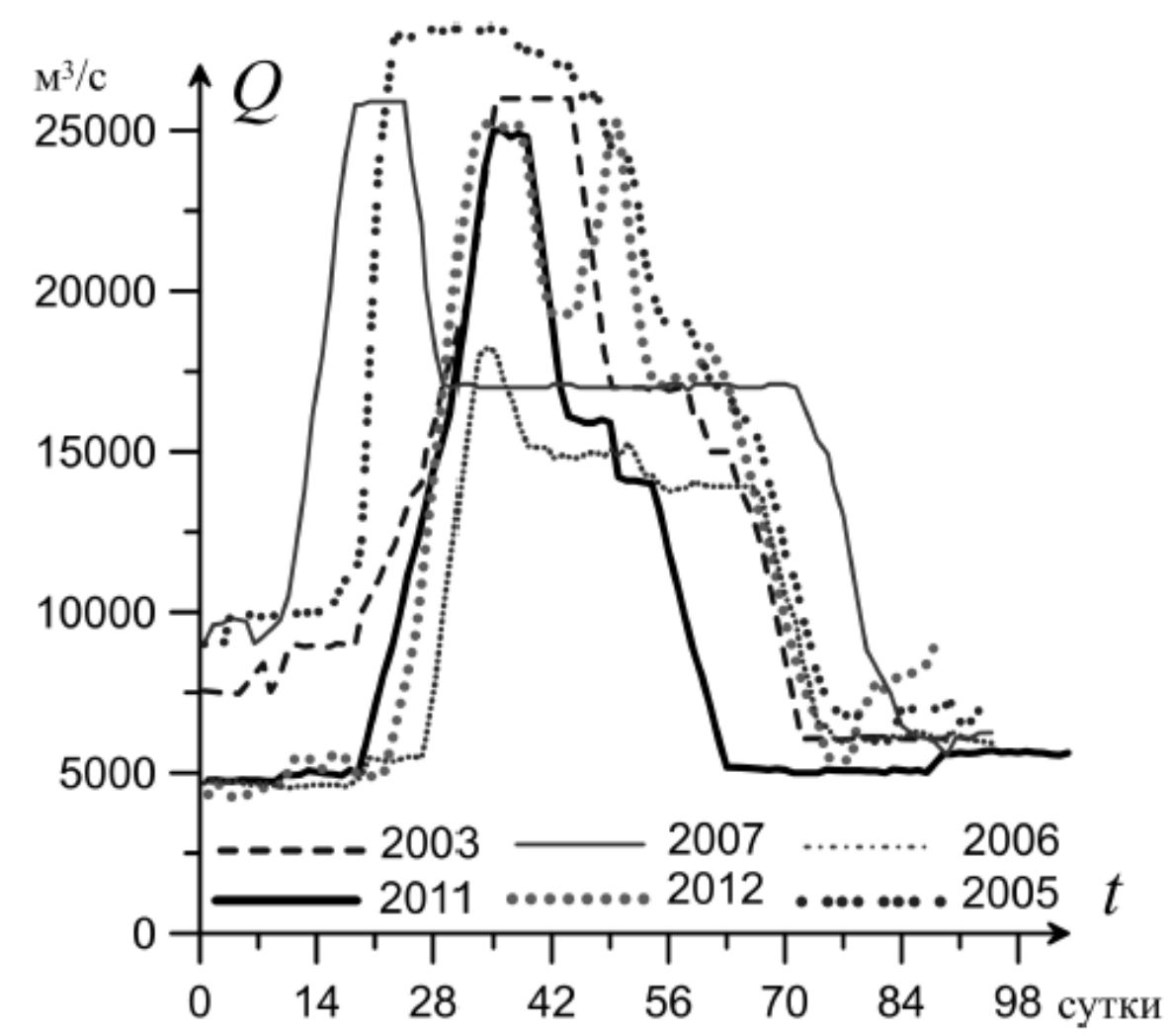

Рис 3. Паводковые гидрографы Волжской ГЭС

2. Морфометрия и пропускная способность русловой сети. Данный фактор определяет режим поступления паводковых вод в водотоки ВАП и характер распределения стока на пойменных территориях [Воронин, 2012]. Основные параметры, влияющие на данный фактор:

- заиление основных водотоков - формирование отмелей в истоках приводит к ограничению количества воды, поступающей в пойму,

- заиление мелких водотоков - приводит к обезвоживанию отдельных водоемов.

3. Антропогенное влияние, выразившееся прежде всего в изменении рельефа и принципиальном нарушении условий стока воды и наносов:

- строительство дорог и дамб,

- перекрытие водотоков плотинами,

• уменьшение числа водоемов.

Состояние Волго-Ахтубинской поймы с каждым годом ухудшается [Филиппов, 2012]. Среди ключевых проблем можно выделить следующие:

1. Негативные изменения гидрологического режима;

2. Негативные изменения условий существования и воспроизводства ценных пород рыб;

3. Защита территорий от подтопления;

4. Деградация малых водотоков и водоемов;

5. Проблемы водообеспечения населенных пунктов Волго-Ахтубинской поймы; 
6. Несоответствие запросов отраслей экономики природоохранным требованиям при многоцелевом использовании водных ресурсов.

Решения по улучшению состояния ВАП должны быть комплексными. Увеличение попуска Волжской ГЭС является недостаточной мерой так как:

1) Энергетики не заинтересованы в продолжительном сбросе. Максимальное количество воды, которое можно пропустить через турбины Волжской ГЭС для выработки электроэнергии - 16000 кубометров в секунду. Для эффективного обводнения ВАП требуется не менее 26000 кубометров в секунду. То есть часть воды спускается вхолостую.

2) Для обводнения поймы на уровне 60-х годов прошлого века требуется увеличить объем паводковых вод. На рис. показано, что при одной и той же величине сброса уровень воды в 2010-2012 гг. ниже, чем в 1961 г. (измерения по гидропосту Волгоград). При сбросе 17000 кубометров в секунду (пунктирная линия) разница составляет 1 метр. Таким образом, для эффективного затопления поймы на рыбохозяйственной полке необходимо держать сброс 20000 кубометров в секунду вместо 17000 кубометров в секунду.

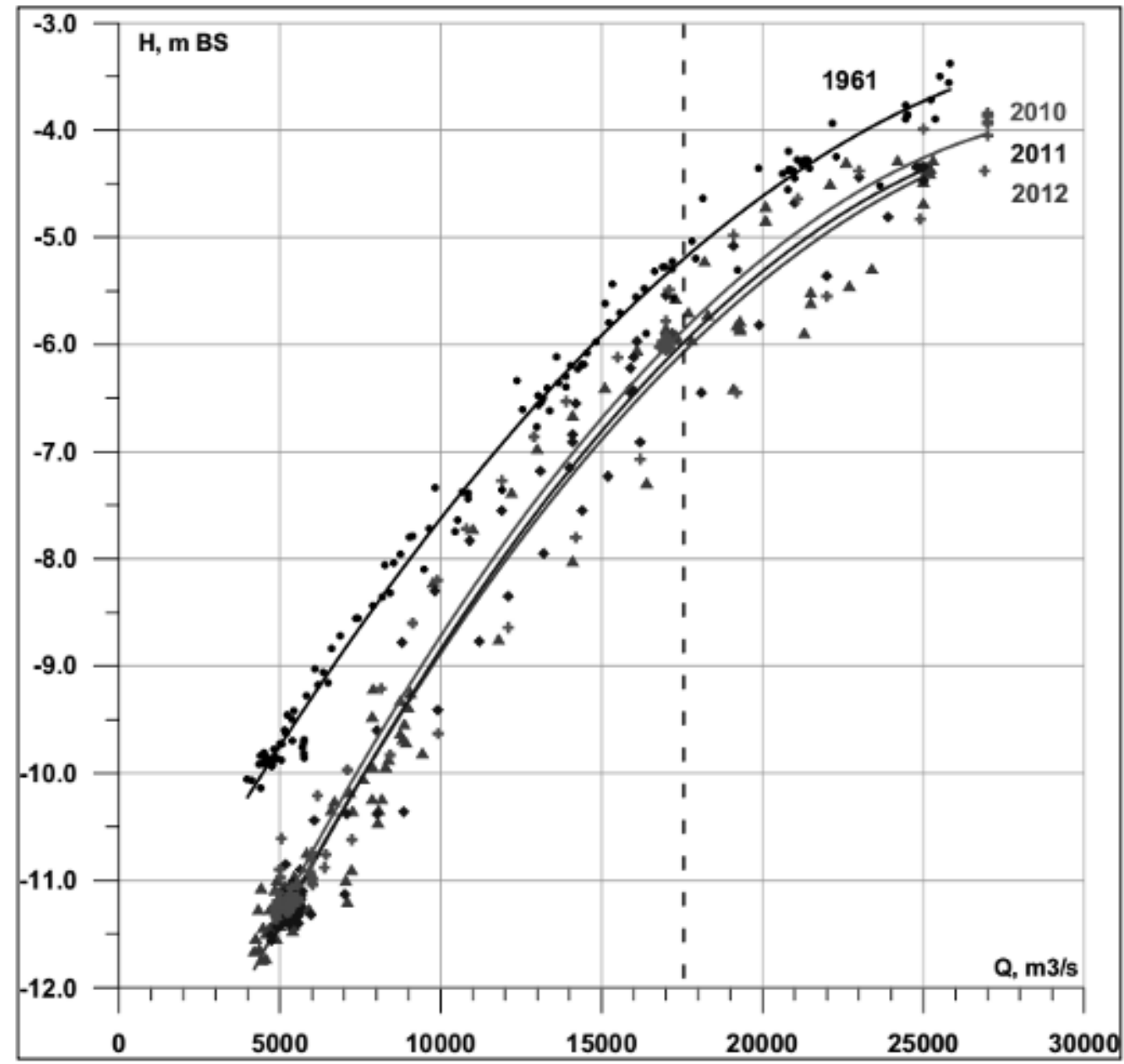

Рис 4. Зависимость уровня воды по гидропосту Волгоград от сброса Волжской ГЭС за разные годы [Горелиц, 2013]

3) За последние 50 лет в пойме появилось много объектов инфраструктуры, которые не рассчитаны под увеличенный попуск Волжской ГЭС и находятся в зоне возможного затопления. 
Периодически появляющиеся проекты по выведению части земель ВАП из состава природного парка в пользу застройки только усугубляют ситуацию [Филиппов, 2012].

\section{3. ПРОЕКТЫ УЛУЧШЕНИЯ ГИДРОТЕХНИЧЕСКОЙ СЕТИ ВОЛГО-АХТУБИНСКОЙ ПОЙМЫ НА ОСНОВЕ ГЕОИНФОРМАЦИОННЫХ ТЕХНОЛОГИЙ.}

Для реалистичных прогнозов о затоплении территории ключевую роль приобретает качество цифровой модели рельефа местности, которая определяется функцией $b(x, y)$.

Имеющиеся общедоступные топографические карты для целей моделирования динамики затоплений имеют крайне ограниченное применение, обладая недостаточным разрешением, прежде всего, по вертикальной координате. В основе используемого нами подхода лежат данные дистанционного зондирования Земли (Д33) [Храпов, 2012].

После проведения серии компьютерных экспериментов [Хоперсков, 2012], была выявлена серия гидрографов, позволяющих наиболее эффективно (максимизируя площадь паводкового затопления территории при заданном объеме паводкового гидрографа) затопить территорию Волго-Ахтубинской поймы [Воронин, 2012]. Сравнение распределения воды в пойме со спутниковыми снимками за прошлые годы показало, что даже максимальный объем воды V. не позволил обводнить затапливаемые ранее территории.

Путем сравнения полученных численным моделированием расчетных карт паводкового затопления (паводок 2012г.) северной части ВАП с полученными ГИС-моделированием картами потенциального затопления, позволило выявить зоны, не затапливаемые вследствие недостаточной пропускной способности и разветвленности гидросистемы поймы. Результат показан на рис.5 (выделено несколько, с 1 по5). Гидродинамическое моделирование позволило также определить величину дополнительного объема гидрографа, необходимого для гидродинамического затопления незатапливаемых зон. Сравнив затраты на расчистку естественной и строительство искусственной гидросистемы в зонах потенциального затопления со стоимостью электроэнергии, полученной от турбинного использования дополнительного объема паводкового гидрографа в течение выбранного горизонта планирования, можно сделать вывод об эффективности соответствующего гидротехнического проекта. 


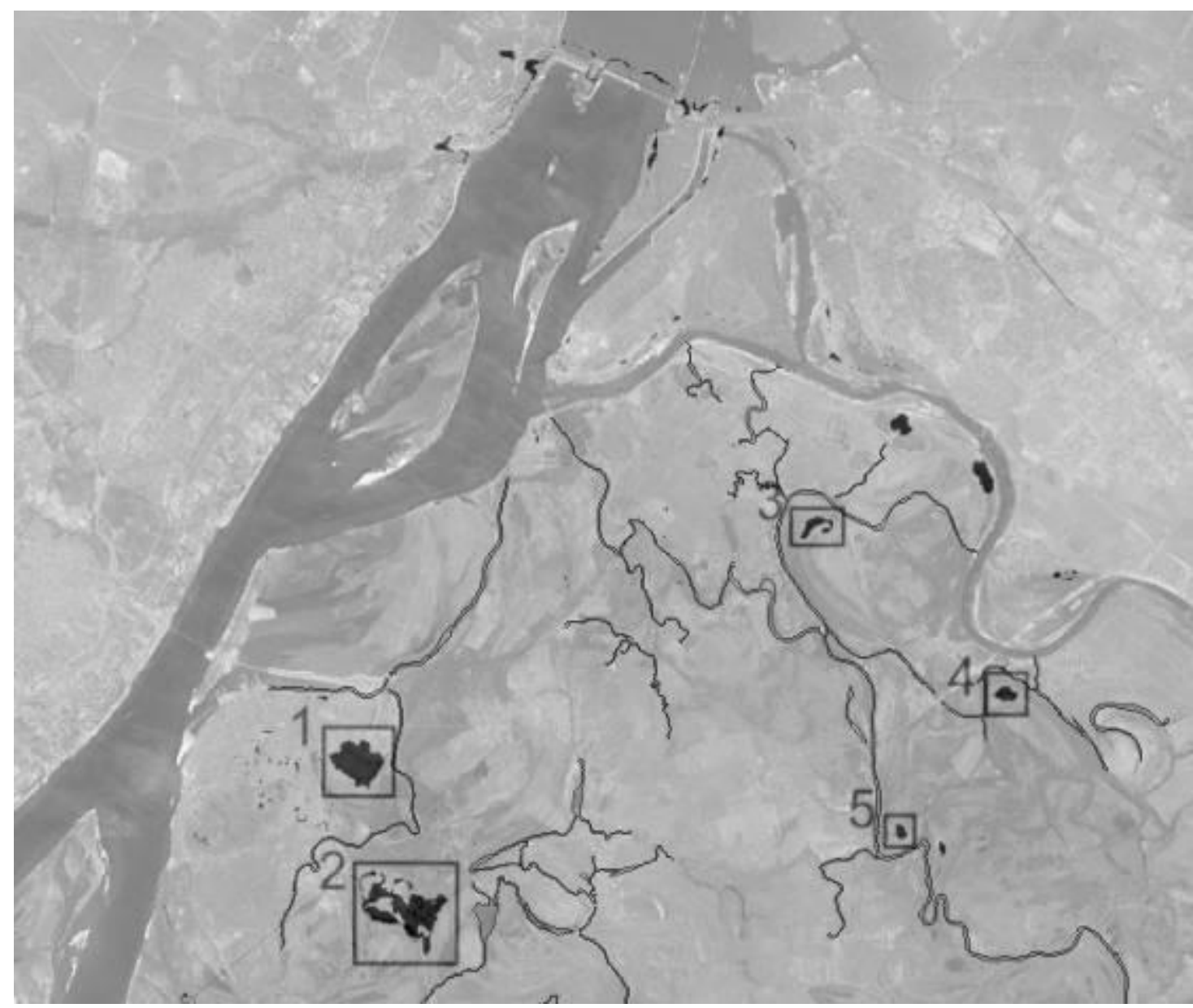

Рис 5. Сравнение динамического и стационарного затоплений в северной части ВАП.

Темными линиями обозначены ерики, пронумерованные площадные фигуры - потенциальные зоны затопления.

На данном этапе все оценки по моделированию виртуальной гидросистемы проводятся вручную после анализа соответствующих картографических данных. Разрабатываемая геоинформационная модель виртуальной гидросистемы позволит строить серии параметрических карт паводковых затоплений. В случае необходимости перекрытия водотока (например, из-за сооружения автомобильной дороги), на карте будет произведен расчет требуемых параметров обходного искусственного канала, сохраняющих режим паводкового затопления ВАП. Более того, в случае несоблюдения Волжской ГЭС планового паводкового гидрографа, проектируемая ГИС-модель позволит рассчитать величину гидрологического ущерба. Расчетный модуль поиска оптимальных карт искусственной гидросистемы включает в себя алгоритм поиска оптимального пути и оценку затрат, учитывающих глубину ерика, перепад высот между уровнем дна и затапливаемой территорией, направление и интенсивность течения, длину канала.

\section{4. ЗАКЛЮЧЕНИЕ}

В целом в низовьях р. Волги требуется системное переустройство водохозяйственного комплекса для оптимизации использования водных ресурсов в целях водоснабжения населения, сельскохозяйственного 
производства, рыбного хозяйства, сокращения холостых сбросов и потерь выработки электроэнергии на гидроэлектростанциях Волжско-Камского каскада, а также сохранения уникальной экосистемы Волго-Ахтубинской поймы и дельты р. Волги. Помимо оптимизации гидрографа, важное значение имеют морфометрические характеристики поймы. Не исключено, что в дальнейшем энергетикам будет выгодней вложиться в совершенствование гидросистемы ВАП для сохранения максимальной площади затопления при меньшем сбросе.

Работа выполнена при частичной поддержке грантов РФФИ 14-07-97030, 14-07-31303_мол, 13-07-97056, 13-01-97062, РГНФ 14-12-34019 и гранта Волгоградской области за 2013 г. (договор № 284).

\section{Литература}

Воронин А.А., Елисеева М.В., Храпов С.С., Писарев А.В., Хоперсков А.В. Задача управления гидрологическим режимом в эколого-экономической системе «Волжская ГЭС Волго-Ахтубинская пойма». Ч. 2. Синтез системы управления // Проблемы управления, 2012, №6. C.19-25. ISSN 1819-3161

Воронин А.А., Елисеева М.В., Писарев А.В., Хоперсков А.В., Храпов С.С. Имитационные модели динамики поверхностных вод с использованием данных дистанционного зондирования: влияние рельефа местности // Прикаспийский журнал: управление и высокие технологии. 2012, No. 3(19), C.54-62.

Горелиц О. В., Землянов И. В. Современный механизм заливания территорий ВолгоАхтубинской поймы в период половодья (в пределах Волгоградской области) //Научный потенциал регионов на службу модернизации. Межвузовский сборник научных статей, №2(5) 2013 , c. $9-18$

Филиппов О.В., Солодовников Д.А., Золотарев Д.В., Канищев С.Н. Опыт восстановления деградированных ландшафтов и водных объектов Волго-Ахтубинской поймы: гидрологический аспект // Вестник Волгоградского государственного университета. Сер. 11, Естественные науки, №2(4), 2012. С. 34 - 43

Хоперсков А.В., Храпов С.С., Писарев А.В., Воронин А.А., Елисеева М.В., Кобелев И.А. Задача управления гидрологическим режимом в эколого-экономической системе «Волжская ГЭС - Волго-Ахтубинская пойма». Ч.1. Моделирование динамики поверхностных вод в период весеннего паводка // Проблемы управления, 2012, №5, 18-25.

Хоперсков А.В., Храпов С.С., Писарев А.В., Кобелев И.А. Геоинформационная система для прогноза сезонных затоплений // Материалы международной конференции «ИнтерКартоИнтерГИС 17» «Устойчивое развитие территорий: теория ГИС и практический опыт». Барнаул (Россия) - Денпасар (Индонезия), 14 - 19 декабря 2011 г. С 190-198.

Храпов С.С., Хоперсков А.В., Писарев А.В., Кобелев И.А., Воронин А.А., Елисеева М.В. Моделирование гидрологического режима Волго-Ахтубинской поймы в период весеннего паводка с использованием программного комплекса «ЭКОГИС» // ИнтерКарто-ИнтерГИС-18: Устойчивое развитие территорий: теория ГИС и практический опыт. Материалы международной конференции / Редкол.: С.П. Евдокимов (отв. Ред.) [и др.]. Смоленск, 26 - 28 июня, 2012 г. Смоленск, 2012. С. 386-394. 
Khrapov S., Pisarev A., Kobelev I., Zhumaliev A., Agafonnikova E., Losev A., Khoperskov A. The Numerical Simulation of Shallow Water: Estimation of the Roughness Coefficient on the Flood Stage // Advances in Mechanical Engineering, 2013, Vol. 2013, Article ID 787016, 11 pages

\title{
ИНТЕГРАЦИОННЫЕ АСПЕКТЫ ЯЗЫКА КАРТЫ В ВИЗУАЛИЗАЦИИ ИНФОРМАЦИИ В ЭПОХУ ИНТЕРНЕТА
}

\author{
A.К. Суворов \\ ОАО «Газпром космические системы» \\ Щёлково, Московская область, Российская Федераџия, suvorov@gazprom-spacesystems.ru
}

\begin{abstract}
INTEGRATION ASPECTS OF THE LANGUAGE OF THE MAP IN THE VISUALIZATION OF INFORMATION IN THE INTERNET ERA
\end{abstract}

\author{
A.K. Suvorov \\ JSC Gazprom space systems \\ Shchelkovo, Moscow Region, Russian Federation, suvorov@gazprom-spacesystems.ru
}

\begin{abstract}
Development of new principles of the language maps associated with the use of the Internet, computers and mobile devices. It is shown that the mapping in the modern society with the use of the Internet is based on ready-made visual images of reality, realization of creative opportunities of people by manipulating these images, posting on the Internet of personal information, implementation of project, mapping and other works on the remote services using Web connection. Describes the developed by the author hermeneutic principles of mapping.

О месте языка карты в визуализации. Использование интернет ресурсов дало мощный толчок развитию народного картосоставления различными слоями населения независимо от профессии, образования, пола, национальности, возраста, в том числе с привлечением своих творческих возможностей, фотографий и зарисовок для отображения геобиогафических событий, объектов, условий, мест, явлений и процессов. В эпоху Интернета виртуальные возможности применения языка карты значительно расширились, ограничениями могут служить только наши знания об окружающем мире и творческие возможности человека в реализации посредством языка карты своих представлений.

Отметим, что наиболее развернутые положения о языке карты были разработаны А.А. Лютым, которые он систематизированном виде изложил в монографии «Язык карты: сущность, система, функции» [Лютый, 2002]. В одной из своих формулировок он дает следующее определение языку карты: «Это объективно существующий феномен, сформировавшийся в общественно-исторической практике человека, передающийся из поколения в поколение путем обучения и приобщения субъектов к соответствующему кругу явлений. Носители этого языка лица, умеющие составлять, читать и понимать карты, сами карты - тексты этого языка, знания о языке (системе, функциях и т.п.), его связях с действительностью, обществом и сознанием
\end{abstract}

